\title{
Resolução de Problemas e Problemas Abertos: Uma Investigação no Ensino de Física
}

\author{
Ubiratãn José Furtado*, André Ary Leonel ${ }^{\star \star}$
}

\section{Resumo}

Este trabalho aborda uma investigação acerca da resolução de problemas no Ensino de Física no âmbito da disciplina de Estágio Supervisionado, realizado em uma turma do segundo ano do ensino médio, tendo como objetivo principal analisar o engajamento dos alunos em práticas de resolução de problemas. Os fracassos observados em avaliações baseadas em resolução de problemas demonstram a necessidade de se trabalhar este assunto em sala de aula por parte do professor e de toda a escola. Estudantes, sem uma preparação para tal, são incapazes de resolver problemas de lápis e papel e problemas abertos em física. A resolução de problemas abertos vai ao encontro de posições filosóficas que defendem uma postura mais ativa do aluno durante o processo de ensino-aprendizagem. Entre outros benefícios, a resolução de problemas contribui para o aprendizado da teoria, para dinamizar a aula e para formar cidadãos mais conscientes do mundo ao seu redor e do impacto de suas ações nele, inclusive fora de sala de aula. Conclui-se então que a resolução de problemas, principalmente os abertos, é uma ferramenta útil em vários aspectos no processo de ensino-aprendizagem, além de ser de baixo custo material, ou seja, não demanda a presença de grandes recursos, podendo ser trabalhada em praticamente qualquer escola.

Palavras-chave: resolução de problemas, problemas abertos, estágio supervisionado, engajamento.

- Licenciando em Física, com doutorado e mestrado em Física pela Universidade Federal de Santa Catarina (UFSC). Pós-doutorado no LPC (Laboratoire de Physique Corpusculaire). Brasil. E-mail: ujfurtado@gmail.com

* Professor do Departamento de Metodologia de Ensino (UFSC) e nos Programas de Pós-graduação em Educação Científica e Tecnológica da UFSC e Educação Matemática e Ensino de Física da UFSM. Brasil. E-mail: andre.leonel@ufsc.br

Recebido em: 22/07/2020 - Aceito em: 11/09/2020.

https://doi.org/ 10.5335/rbecm.v3i2.11370

http://creativecommons.org/licenses/by-nc-nd/4.0 


\section{INTRODUÇÃO}

É de consenso geral entre os pesquisadores da área de ensino de ciências que o ensino, incluindo o Ensino Médio, deve proporcionar o desenvolvimento de habilidades investigativas (PEDUZZI, 1997). Os métodos de ensino devem capacitar os alunos a responder a perguntas e a procurar informações necessárias para a resolução de situações do cotidiano, no trabalho e na vida pessoal. Uma das características que devem ser trabalhadas no processo de aprendizagem é a atitude reflexiva e autocrítica diante de possíveis erros. Um ensino que proporcione a formação de estruturas de raciocínio, fator necessário para uma aprendizagem efetiva, permite aos alunos gerenciarem os conhecimentos adquiridos (BRASIL, PCNEM, 2006). Nesta perspectiva, estratégias de resolução de problemas têm sido elaboradas "para completar a forma de ensino tradicional, permitindo aos alunos terem uma visão diferente da realidade a partir de um estímulo e da reflexão" (BOY \& GARCIA, 2018, p. 143).

Assim, este trabalho versa sobre uma investigação realizada durante a disciplina de Estágio Supervisionado em Ensino de Física C, do curso de Licenciatura em Física de uma Universidade Federal, no ano de 2019, tendo como principal objetivo analisar o engajamento dos alunos em práticas de resolução de problemas. Os assuntos de física trabalhados foram o Ciclo de Carnot e Máquinas Térmicas. Como presente no PCN+ do Ensino Médio:

A presença do conhecimento de Física na escola média ganhou um novo sentido a partir das diretrizes apresentadas nos PCN. Trata-se de construir uma visão da Física que esteja voltada para a formação de um cidadão contemporâneo, atuante e solidário, com instrumentos para compreender, intervir e participar na realidade. Nesse sentido, mesmo os jovens que, após a conclusão do ensino médio não venham a ter mais qualquer contato escolar com o conhecimento em Física, em outras instâncias profissionais ou universitárias, ainda assim terão adquirido a formação necessária para compreender e participar do mundo em que vivem. (PCN+ - Física, p. 01)

Para justificar a importância de se trabalhar estes assuntos, cabe reforçar as Competências Gerais do PCN+ do Ensino Médio. Entre as principais competências que podem ser trabalhadas com estes assuntos, salientamos as seguintes: a) Discussão e argumentação de temas de interesse da C\&T, pois as máquinas térmicas estão presentes no cotidiano da população em geral, inclusive dentro das nossas 
casas (refrigeradores e ar condicionado), e tiveram um importante papel histórico na Primeira Revolução Industrial; b) Estratégias para enfrentamento de situações-problema, pois diante de algumas situações se faz necessário reconhecer a natureza dos fenômenos envolvidos, situar dentro de uma área da Física e identificar as grandezas relevantes; c) Interações, relações e funções, invariantes e transformações, pois diante de algumas situações se faz necessário estabelecer relações entre grandezas; d) Ciência e tecnologia na história, ou seja, compreender o conhecimento científico e tecnológico como uma construção humana, e que a construção desse conhecimento se dá em um contexto histórico e social, inclusive alterando a realidade da sociedade ou até mesmo do planeta todo; e) Ciência e tecnologia na cultura contemporânea e na atualidade, ou seja, saber como a ciência e a tecnologia afetam a sociedade de hoje em dia.

Nesta direção, ao final do conjunto de aulas planejadas, em relação a aprendizagem em Física, era almejado que os alunos soubessem identificar a importância das transformações termodinâmicas e a importância de se procurar diminuir as perdas de energia útil durante essas transformações. Em relação à formação dos alunos num contexto mais geral, pensando na formação científica e tecnológica e também na formação para a vida, almejava-se trabalhar algumas das competências citadas no parágrafo anterior e os benefícios das áreas de ensino de física na qual as aulas foram baseadas, Resolução de problemas e Problemas abertos, discutidas nas próximas seções, como uma maior autonomia para tomar ações e buscar soluções para diversos problemas que possam aparecer durante toda a vida do estudante, inclusive depois de sair da escola.

\section{RESOLUÇÃO DE PROBLEMAS}

Muitas vezes é comum imaginar que se os alunos possuem o conhecimento conceitual sobre algum assunto, eles são então capazes de resolver problemas por si próprios, mesmo sem um treinamento para tal. No entanto, o observado na prática é diferente, inclusive entre professores (GIL-PEREZ et al., 1988; PEDUZZI, 1997; GUISASOLA et al., 2015). Frequentemente, as avaliações baseadas em problemas não obtêm resultados satisfatórios. Além disso, isso dificulta a avaliação do nível de conhecimento dos alunos sobre o assunto em questão, ainda mais quando se leva em conta que as avaliações baseadas em problemas são a maioria. A resolução de 
problemas em física, e em outras áreas do conhecimento, deve ser trabalhada em sala de aula, podendo ser uma importante ferramenta para o processo de ensino-aprendizagem. O professor, e a escola como um todo, devem considerar a resolução de problemas como parte integrante do ensino, e atividades sobre o assunto certamente resultarão em alunos com uma maior autonomia em suas ações em vários momentos de suas vidas.

Durante o percurso da vida, as pessoas enfrentam situações onde devem tomar decisões e buscar soluções para diversos problemas, seja no trabalho, nos estudos, ou até mesmo no cotidiano pessoal. Não são somente os estudantes e os cientistas que possuem problemas para resolver.

Diz-se que uma situação é um problema para uma pessoa quando a solução, ou a tomada de uma decisão, não é óbvia, não é automática para esta pessoa. Ou seja, é necessário refletir sobre o assunto e a solução é encontrada através de uma sequência de passos e/ou tomada de decisões (ECHEVERRÍA \& POZO, 1994 apud PEDUZZI, 1997). Diferentemente, em um exercício, são usadas rotinas automatizadas, já conhecidas pelo solucionador.

Desta forma, uma situação que é um exercício para uma pessoa pode ser um problema para outra. Não deve-se então afirmar que uma situação é um problema ou um exercício sem levar em conta a pessoa a quem se apresenta tal situação.

Num ambiente de estudos, à medida em que um estudante adquire conhecimento e desenvolve novas habilidades, uma situação que inicialmente é um problema, pode passar a ser apenas um simples exercício.

A resolução de problemas não deve ser deixada em segundo plano no processo de ensino. É através dela que o aluno consolida o conhecimento e desenvolve habilidades. Entretanto, os alunos podem não dar-se conta disso por conta própria, tornando a resolução continuada de problemas e exercícios não atrativa e cansativa. O professor deve, então, trabalhar também os propósitos dos exercícios e dos problemas em sala de aula, contribuindo para a evolução do aluno neste quesito (PEDUZZI, 1997; GIL-PEREZ et al., 1988). Inclusive simples exercícios podem requerer uma discussão mais aprofundada por parte do professor (GUISASOLA, 2015).

Contudo, observa-se que os professores de física, durante a explicação de um exemplo, fazem uma sequência de passos como se fossem óbvios, inclusive para os alunos. Ou seja, o professor trata o problema como um exercício. Ele não incita o questionamento por parte dos alunos e não trabalha o fato de que algumas tentati- 
vas de solução podem não dar certo, inclusive da parte dele. Quando os alunos vão enfrentar problemas sozinhos, eles então sentem dificuldades para solucioná-los, pois não receberam formação satisfatória para tal prática. Tal situação tem sido causa de parte da falta de motivação para o estudo da Física e da sensação de incapacidade para a resolução de problemas. Porém, muitos professores consideram que as causas dos fracassos dos alunos na resolução de problemas se dão devido a uma não compreensão dos temas estudados e/ou conhecimentos deficitários de matemática, sem questionar a própria didática.

Diante do exposto acima, a resolução de problemas assume um papel de grande relevância no processo de ensino-aprendizagem de Física e por isso deve ser estudada e investigada. Neste sentido, para contribuir com estas questões e com os objetivos deste trabalho, discutimos, a partir da literatura da área, etapas para a resolução de problemas.

Etapas na resolução de problemas

Peduzzi (1997) apresenta vários autores propõem uma classificação das etapas ou fases presentes na resolução de problemas. Para o autor estas classificações deixam de fora fatores psicológicos, como ansiedade, motivação, destreza, influência de experiências anteriores, etc. Para Kuhn (1987) não deve-se sugerir que somente se ataque um problema após dominar por completo a teoria, pois a teoria também é aprendida na busca de soluções para determinados problemas.

Há também pesquisas na área de resolução de problemas em que não apontam um caminho evidente para se atingir o objetivo, com alguns se enquadrando na categoria de problemas abertos.

Quando se procura classificar as etapas efetuadas por um especialista (professor ou cientista) na abordagem a um problema de ciências naturais, verifica-se, normalmente, o seguinte: primeiro o problema a ser tratado é identificado; em seguida, são formuladas hipóteses e modelos são construídos; o próximo passo é a comparação dos dados fornecidos pelos modelos aos dados reais; a interpretação destes dados, os limites de aplicação do experimento e dos modelos, o potencial de previsão destes, a proposição de novos experimentos e a confirmação ou a necessidade de alterações dos modelos são por último analisados.

$\mathrm{Na}$ resolução de problemas com objetivo de aprendizagem, de um modo bem geral, os passos são similares (KRAMERS-PALS \& PILOT, 1988 apud PEDUZZI, 
1997): análise do problema (fase 1); planejamento do processo de resolução (fase 2); resolução de fato (fase 3); análise e interpretação da resposta (fase 4). Mas qual é o papel do professor neste processo?

\section{O papel do professor no desenvolvimento de habilidades para a resolução de problemas}

Apenas observar o professor resolvendo problemas de maneira linear, como citado antes, não fornece o sucesso desejado aos alunos por parte das instituições escolares. Os professores não enxergam a necessidade de trabalhar a resolução de problemas mais do que é normalmente trabalhada. Ironicamente, os alunos são avaliados basicamente através de problemas.

Como explorar então as habilidades do professor em resolver problemas em favor do processo de ensino-aprendizagem?

Apenas solicitar ao professor para descrever os passos durante a resolução de um problema pela primeira vez, não necessariamente garante que todos os passos sejam realmente descritos, é possível que apenas os passos julgados corretos sejam enunciados, consciente ou inconscientemente. Uma análise retrospectiva também padece do mesmo mal e talvez alguns passos possam ser esquecidos.

Observar criticamente como os alunos abordam um problema pode ajudar a identificar as características de bons e maus solucionadores e dificuldades enfrentadas pelos alunos. Pesquisas já desenvolvidas mostram que existem grandes diferenças entre a abordagem de bons e maus solucionadores, ou especialistas e iniciantes (LARKIN \& REIF, 1979; LARKIN \& McDERMOTT, 1980; ROSA, MOREIRA \& BUCHWEITZ, 1992; ZAJCHOWSKI \& MARTIN, 1993 apud PEDUZZI, 1997).

Vários passos tomados por um especialista na resolução de problemas não são perceptíveis, mesmo aos observadores atentos, pois são feitos mentalmente, de forma abreviada, e alguns até inconscientemente. Normalmente, apenas a parte da resolução de fato é mais visível.

'Na fase 1, a parte escrita limita-se frequentemente ao rabisco de alguns dados. Na fase 2, o loop 2b-2c [planejamento] não é em geral comentado, porque a maioria dos problemas são meras rotinas para o professor (exercícios). A conferência dos resultados, tão usual ao especialista, também é feita mentalmente. Como, então, podem os estudantes aprender a fazerem uma cuidadosa análise do problema, a 
planejarem os passos relativos à solução e a avaliarem os resultados se eles não veem o professor fazendo isso?' (KRAMERS-PALS \& PILOT, 1988 apud PEDUZZI, 1997, p. 237).

Cabe também aos livros didáticos o papel de capacitarem os estudantes para a resolução de problemas. É oportuno aqui, que apesar das críticas às estratégias gerais, elas não devem ser descartadas, pois podem, além de promover uma discussão sobre a importância da resolução de problemas no processo de ensino-aprendizagem, fornecer elementos e inspiração para que os estudantes desenvolvam suas habilidades e também suas próprias estratégias de resolução de problemas.

\section{Uma estratégia para a resolução de problemas em física básica}

A estratégia a seguir é apresentada por Peduzzi (1997) e reproduzida fielmente aqui. As fases da estratégia (que, segundo o autor, não estão ordenadas por hierarquia ou ordem de importância) para a resolução de problemas de física básica são:

1. Ler o enunciado do problema com atenção, buscando à sua compreensão;

2. Representar a situação-problema por desenhos, gráficos ou diagramas para melhor visualizá-la;

3. Listar os dados (expressando as grandezas envolvidas em notação simbólica);

4. Listar a(s) grandeza(s) incógnita(s) (expressando-a(s) em notação simbólica);

5. Verificar se as unidades das grandezas envolvidas fazem parte de um mesmo sistema de unidades; em caso negativo, estar atento para as transformações necessárias;

6. Analisar qualitativamente a situação problema, elaborando as hipóteses necessárias;

7. Quantificar a situação-problema, escrevendo uma equação de definição, lei ou princípio em que esteja envolvida a grandeza incógnita e que seja adequada ao problema;

8. Situar e orientar o sistema de referência de forma a facilitar a resolução do problema;

9. Desenvolver o problema literalmente, fazendo as substituições numéricas apenas ao seu final ou ao final de cada etapa;

10. Analisar criticamente o resultado encontrado; 
11. Registrar, por escrito, as partes ou pontos chave no processo de resolução do problema;

12. Considerar o problema como ponto de partida para o estudo de novas situações-problema.

Pode parecer que o modelo acima possui muitas etapas, porém ele é similar aos outros apresentados na literatura. O primeiro ponto realça a importância da leitura com atenção do problema, buscando a identificação do que o problema pede e um entendimento geral do problema. O segundo ponto também se preocupa com o entendimento do problema, mas chama a atenção ao fato de que a representação deste de outras formas pode ser útil, principalmente para os alunos que têm um desempenho melhor com processos de aprendizagem mais visuais. Os terceiro e quarto passos, além de também ajudar no entendimento do problema, contribuem para uma resolução mais organizada e fazem a relação das grandezas físicas com as letras usadas nas fórmulas matemáticas. $\mathrm{O}$ quinto ponto ajuda a evitar erros simples no futuro. O sexto passo é um dos mais importantes. É nele que os alunos farão considerações sobre o problema antes de lidarem com as equações. Quais são as aproximações feitas, quais são os princípios e leis que são válidos e podem ser usados, etc. Isto contribui para a aprendizagem dos assuntos envolvidos no problema, além do desenvolvimento da capacidade de julgamento dos alunos sobre hipóteses, para ver se elas são pertinentes ou não. Os problemas abertos, como os propostos por Gil-Perez (GIL-PEREZ \& MARTINEZ-TORREGROSA, 1987; GIL-PEREZ et al., 1988; GIL-PEREZ et al., 1992), são de grande ajuda nestes quesitos. Em problemas fechados há pouca margem para a emissão de hipóteses.

Ocorre que a estrutura usual dos problemas de lápis e papel, em física, calcada na busca de uma conexão entre dados e incógnitas, induz o estudante a considerar o conhecimento como resultado de um processo indutivo de inferência a partir de dados conhecidos, isto é, a uma visão empirista da ciência. [...] É importante ressaltar que a metodologia proposta por Gil-Perez para a abordagem de problemas sustenta-se, teoricamente, no desenvolvimento de um ensino em conformidade com certos aspectos consensuais da moderna filosofia da ciência (Kuhn, Popper, Lakatos, Toulmin, Hanson etc.). Isto é, em um ensino que deve destacar o papel central da 
hipótese e do conjunto de pressupostos teóricos do cientista na proposição, delineamento, articulação e seleção de teorias. (PEDUZZI, 1997, p. 242)

O sétimo passo é escrever as fórmulas e equações que contêm as incógnitas e que sejam adequadas ao problema. Para os pontos 6 e 7, é fundamental que os alunos possuam conhecimentos sobre a matéria estudada, sendo necessário uma aula sobre isso antes de se atacar um problema. Os oitavo e nono pontos tratam da simplificação matemática e da execução das operações. Ao final, deve-se analisar se os resultados encontrados possuem sentido físico e se são razoáveis de acordo com a situação estudada. Os dois últimos pontos são voltados ao ensino, para um processo de aprendizagem continuada.

\section{PROBLEMAS ABERTOS}

Em diversas áreas, os profissionais mais valorizados são os que, usualmente, são capacitados a resolverem problemas abertos, como um médico que consegue diagnosticar uma doença difícil de ser identificada.

Problemas abertos, por definição, não possuem soluções preestabelecidas. Em geral referem-se a um evento do mundo real e apresentam estado inicial só parcialmente conhecido. Ou seja, os alunos precisam fazer a relação com o que é de seu conhecimento e construir uma resposta consistente com a realidade e é, geralmente, necessário "fazer uso de idealizações, estimativas, aproximações, lançar hipóteses, testar a solução, monitorar e regular os procedimentos metodológicos e as próprias atividades cognitivas durante a tentativa de resolução do problema." (OLIVEIRA, ARAUJO \& VEIT, 2017, p. 2)

Ainda em (OLIVEIRA, ARAUJO \& VEIT, 2017), diversos argumentos de outros trabalhos em defesa do uso de atividades didáticas de resolução de problemas abertos no ensino de física são citados. Entre os argumentos já apontados pelos autores supracitados, cabem destaque os seguintes: o uso de problemas abertos promove a aprendizagem dos alunos, sendo úteis para o tratamento de vários conteúdos de Física (conceitos, princípios e modelos) e também para o tratamento de procedimentos (técnicas, estratégias de solução, argumentação) e atitudes (juízos, normas e valores) (CLEMENT \& TERRAZZAN, 2012); podem proporcionar a aquisição, solidificação 
e aplicação de conhecimento científico a partir de uma perspectiva pedagógica (ABDULLAH, 2014); em (PIZZOLATO et al., 2014), é afirmado que as dificuldades tanto conceituais quanto epistemológicas em resolver problemas poderiam ser superadas introduzindo os alunos em um ambiente de raciocínio científico, promovido por processos de investigação via resolução de problemas abertos; similarmente, em (BARKOVICH \& CARREÑO, 2013) e (LABURÚ, 2003), é argumentado que problemas abertos exigem procedimentos que se aproximam do trabalho científico, como análise qualitativa de uma situação, delimitação do problema a partir de hipóteses adequadas, seleção das variáveis, etc; a dinâmica da aula muda, na qual os alunos assumem uma postura mais ativa e acabam expondo algumas deficiências em seu conhecimento (ROBINSON, 2008); promovem o trabalho colaborativo e auxiliam na transição entre o cotidiano e a compreensão de conceitos físicos (ENGHAG, GUSTAFSSON \& JONSSON, 2009); aumento da capacidade criativa dos estudantes (DIAKIDOY \& CONSTANTINOU, 2001); promoção do pensamento crítico (ERCEG, 2013); e podem contribuir para a superação da falta de interesse dos estudantes, possivelmente relacionada às abordagens abstratas, desvinculadas do mundo real (HUNSCHE \& AULER, 2012).

Apesar dos vários argumentos citados no parágrafo anterior, atividades envolvendo a resolução de problemas abertos raramente são implementadas no ensino. Há apenas a resolução de exercícios e problemas típicos dos livros didáticos, e não se procura desenvolver habilidades para a resolução de problemas abertos. Em vista disso, os alunos se preocupam em memorizar algoritmos para usarem nas avaliações, usualmente baseada em exercícios e problemas tradicionais.

Há uma polissemia da expressão problema aberto na literatura (OLIVEIRA, ARAUJO \& VEIT, 2017). Entre as definições encontradas estão: problemas mal estruturados/mal definidos, que não são resolvidos por procedimentos pré-definidos, o caminho para a resolução não é evidente, ou bem estruturados/bem definidos, que possuem todas as informações necessárias para resolvê-los, o conjunto de regras para isso é limitado e o caminho para a resolução é, muitas vezes, lógico e único; diferença entre exercícios, que podem ser resolvidos por aplicação de um procedimento rotineiro, e problemas autênticos, que exigem um processo de reflexão, que exigem hipóteses e decisões. Portanto, a distinção entre exercícios e problemas depende do conhecimento prévio do solucionador; problemas padrão, nos quais são fornecidos todos os dados necessários para a resolução e deve-se encontrar uma 
resposta bem definida, e problemas do mundo real, os quais devem estar relacionados a um contexto autêntico, com informações consistentes com a realidade e, os quais devem ser delimitados pelo solucionador, hipóteses, simplificações, escolha de modelos, etc, devem ser feitas; problemas bem contextualizados, com o objetivo de desenvolver uma análise sobre eventos reais, mas em que são necessários fornecer algumas informações, descobrir qual é a variável de interesse, etc; por último, há os Fermi problems, com pouca ou nenhuma informação.

Problemas abertos estão presentes no cotidiano de todos. É interessante notar que, embora não haja um consenso sobre o que é um problema aberto, existem algumas características em comum entre as diferentes definições, como a indefinição de elementos do problema, diferentes soluções e caminhos para uma resposta, incerteza sobre os procedimentos para se encontrar a resposta, necessidade de conhecimentos de domínio e de conhecimentos procedimentais e a necessidade de se fazer julgamentos. É consenso também que atividades com este assunto podem contribuir de diversas maneiras para a aprendizagem e formação dos estudantes.

\section{A INVESTIGAÇÃO}

Tendo em vista os argumentos supracitados, buscou-se trabalhar problemas abertos em uma turma de Ensino Médio, acreditando ser possível trabalhar a questão de resolução de problemas e problemas abertos. $O$ fato de trabalhar os problemas em grupo, como o proposto, poderia ser motivante para os menos interessados, ou ao menos gerar um empenho maior destes nas atividades. Havia ainda a necessidade de se trabalhar os conteúdos de física de acordo com o solicitado pela professora do colégio, devido ao cronograma que tinha de ser seguido, e pensamos que esta área temática poderia se adequar a este propósito, em vista também dos conteúdos de física que seriam trabalhados. Temos então uma situação onde o conteúdo trabalhado fazia parte do currículo.

O estágio foi realizado numa turma de segundo ano do Ensino Médio, do Colégio de Aplicação (CA) de uma Universidade Federal, no segundo semestre de 2019. Desde 1992, o ingresso de alunos no Colégio ocorre via sorteio aberto à comunidade. Dá página na internet do CA, obtemos as seguintes informações: 
"Enquanto escola experimental, o Colégio tem proporcionado o desenvolvimento de experiências pedagógicas e estágios supervisionados para os cursos de Licenciatura e Educação, segundo as exigências da Lei no ${ }^{\circ}$ 9394, de 20 de dezembro de 1996 (LDB).

Atualmente o Colégio de Aplicação, inserido no Centro de Ciências da Educação[...], é uma unidade educacional que atende ao Ensino Fundamental e Médio, [e] funciona em prédio próprio, no Campus Universitário[...].

O Colégio de Aplicação segue a política educacional adotada pela Universidade [...] que visa atender à trilogia de Ensino, Pesquisa e Extensão.

No presente momento, o Colégio de Aplicação está em processo de implementação do seu Projeto Político-Pedagógico, que foi concebido a partir de uma proposta de gestão participativa."

O CA possui uma boa estrutura física, com diversos laboratórios de ensino, inclusive de Física. As turmas possuem em média 25 alunos, número menor do que de outras escolas da região. Os professores de uma dada disciplina possuem salas próprias, além de um tempo maior para preparar as aulas do que professores de escolas do estado.

A turma na qual o estágio foi realizado contava com 26 alunos, mas sempre havia faltas ou alunos participando de outras atividades, como alguns alunos que viajaram ao exterior por alguns meses por conta de projetos e parcerias do CA com outras instituições.

Antes do planejamento e desenvolvimento da prática, foram observadas algumas aulas para que o estagiário conhecesse a características da turma e tivesse um primeiro contato. As aulas ministradas pela professora foram basicamente tradicionais, expositivas, com perguntas aos alunos. Porém, devido ao tempo disponível, a professora acabava por responder muitas das próprias perguntas para que a aula prosseguisse. A turma em geral tinha boa participação e dispersões da aula eram facilmente contornadas pela professora.

Diante do observado, o planejamento foi composto de três encontros de duas aulas cada, em três dias diferentes. Como argumentado antes, é necessário um primeiro contato com o assunto antes de se atacar um problema, para que, entre outras coisas, desperte o interesse no aluno, este não se sinta desmotivado com dificuldades do problema, e para que o ensino avance mais rapidamente. O encontro 1 foi dedicado para isso. Ele correspondeu a uma aula de caráter tradicional, 
com perguntas aos alunos, sobre processos cíclicos, o ciclo de Carnot, processos reversíveis e irreversíveis e entropia. Ao final da aula, esperava-se que os alunos soubessem identificar o que é um processo cíclico, diferenciar processos reversíveis e irreversíveis e que tivessem uma noção sobre o conceito de entropia. No final da aula, foi realizada uma experiência demonstrativa sobre entropia com uma caixa e grãos de diferentes tipos, inicialmente separados. Após chacoalhar a caixa, observou-se as posições dos grãos. Como a primeira aula tinha um caráter tradicional, a prática correspondeu ao planejado. Por último, foi entregue uma lista de problemas, para ser devolvida uma semana depois, compondo parte da avaliação. A lista era composta por problemas abertos ou semiabertos. Cabe relembrar aqui que, como já dito por Clement e Terrazzan (2012), Peduzzi (1997) e Guisasola et al. (2015), algumas situações podem se constituir em problemas para alguns e em exercícios para outros. Desta forma, o auxílio do professor neste momento é fundamental para o avanço em direção aos objetivos.

Antes de iniciar as atividades dos encontros 2 e 3, algumas dúvidas sobre a lista de problemas foram tiradas em sala de aula. Os alunos foram questionados sobre as dúvidas, e indicações sobre como resolver os problemas que foram propostos foram dadas. Em especial, o caráter aberto dos problemas foi o que gerou mais dificuldades.

Para o segundo encontro foi solicitado que os alunos, em grupos, construíssem teoricamente um motor a base d'água e de vapor d’água, operando em ciclos, como previsto no planejamento. Mais precisamente, foi solicitado aos alunos que construíssem um motor pensando as partes e o funcionamento deste, usando os conhecimentos das aulas anteriores, inclusive de assuntos trabalhados antes do início do estágio pela professora da turma. Somente após essa parte feita, os alunos deveriam pensar em construir um gráfico da pressão versus volume $(\mathrm{P} \times \mathrm{V})$ com as transformações ocorridas.

Após deixar um tempo para que os alunos pensassem sobre o problema, foi passado em cada grupo para ver o andamento do que foi solicitado. Mesmo solicitando que os alunos construíssem um motor pensando as partes e o funcionamento do motor, os alunos pensaram apenas em fazer um gráfico $\mathrm{P}$ x V, ou seja, os alunos não fizeram a relação com a realidade ou não prestaram atenção ao que foi orientado.

Foi repetida a explicação em cada grupo, reforçando no que era esperado. Antes do final da aula, foi distribuído uma folha de papel para cada grupo para que escrevessem o que fizeram até aquele momento. Mesmo com as explicações, apenas 
um grupo entendeu e fez parte do esperado. Os outros grupos apenas entregaram a repetição do que foi explicado.

Devido ao andamento lento da atividade, não foi possível fazer a discussão das propostas dos diferentes grupos, como previsto no planejamento. Ficou clara a dificuldade dos alunos em fazer uma atividade diferente do que estão acostumados. Além disso, foi percebido muita conversa alheia ao problema, prejudicando a atividade. Não foi comentado sobre a possibilidade de se usar ou não o livro didático, pois nele havia uma resposta pronta ao problema. No entanto, um grupo pensou em usá-lo, o que não foi permitido. Nos outros grupos não foi necessário falar nada.

Os minutos iniciais do terceiro encontro foram deixados para esclarecimento de dúvidas sobre a lista de problemas. Após as dúvidas, os alunos entregaram a tarefa, como previsto. Dois alunos não a entregaram.

Em seguida, foi solicitado a um aluno do grupo, que tinha feito a atividade anterior de forma mais completa, para que explicasse o que tinham pensado no quadro. O estagiário ajudou a explicar partes que talvez não tivessem sido bem explicadas. Como os outros grupos não tinham proposto algo diferente, e devido ao tempo curto, as respostas apresentadas não foram confrontadas.

Em seguida, foi solicitado para que os alunos, em grupos, construíssem teoricamente uma geladeira a base d'água e de vapor d'água, operando em ciclos, como também previsto no planejamento. As mesmas orientações do encontro anterior foram dadas, ou seja, foi pedido para que os alunos construíssem uma geladeira pensando as partes e o funcionamento desta, usando os conhecimentos das aulas anteriores, inclusive de assuntos trabalhados antes do início da prática. Foi enfatizado que esta primeira parte era a mais importante, e somente após essa parte feita é que deveriam pensar em construir um gráfico $\mathrm{P}$ x V com as transformações ocorridas.

Como antes, após deixar um tempo para que os alunos pensassem sobre o problema, foi passado em cada grupo para ver o andamento do que foi solicitado. Diante da dificuldade dos alunos, desta vez foi permitido o uso do livro didático, para ver se as propostas melhorariam.

Desta vez, houve uma melhora considerável nas propostas entregue. Entre os motivos pensados para essa melhora estão um contato com esse tipo de atividade no encontro anterior e a possibilidade do uso do livro didático. Com a exceção de um dos seis grupos, todos entregaram uma proposta para o funcionamento da geladeira, nas 
quais explicaram o que ocorre em cada parte. No entanto, nenhum grupo conseguiu identificar as transformações termodinâmicas que ocorrem em cada etapa, muito menos fazer um gráfico $\mathrm{P} \times \mathrm{V}$ a tempo. Conversas alheias ao problema novamente prejudicaram o andamento da atividade.

Nos minutos finais, foi solicitado ao mesmo aluno da atividade anterior para explicar o funcionamento do proposto. Não houve tempo para uma discussão mais profunda e um confrontamento de propostas também não contribuiria muito pois, devido ao auxílio do livro, as propostas ficaram parecidas.

Durante as atividades dos encontros 2 e 3, os alunos foram incentivados a pensar por si próprios. Acreditamos assim que habilidades para a resolução de problemas pudessem ser melhor desenvolvidas. Os problemas trabalhados foram o mais aberto possível e, quando necessário, interferimos auxiliando os alunos de acordo com a sua dificuldade.

Isto posto, as aulas almejavam trabalhar com a resolução de problemas abertos e semiabertos, para desenvolver as habilidades dos alunos e consolidar nestes o conhecimento conceitual e teórico do assunto estudado.

\section{ANÁLISE SOBRE O TRABALHO DESENVOLVIDO}

Devido ao tempo tomado por algumas atividades, não foi possível seguir o planejamento completamente, principalmente nos encontros 2 e 3, demandando algumas adaptações. Isto serviu para mostrar a importância da flexibilidade do plano a partir de ciclos de experimentação e reflexão sobre a prática. Quanto mais experiente é o professor em preparar e ministrar tais atividades, mais efetivo será o ensino. Será mais fácil para ele escolher uma estratégia de ensino, em função da matéria e da turma em questão. O mesmo vale para os alunos, quanto mais eles estão acostumados com atividades diferentes, menor será o estranhamento e menos dificuldades surgirão.

Os alunos ficaram em dúvida sobre o que foi dito com "Forneça valores ao final”, em alguns problemas do questionário. O objetivo era que os alunos identificassem quais grandezas eram necessárias para a solução e fornecessem valores de acordo com o estudado até o momento e com o seu cotidiano. Não houve tempo para trabalhar problemas abertos deste tipo com os alunos na primeira aula. No início da segunda aula, este ponto foi esclarecido. Acreditamos que três encontros 
é pouco para o que se pretendia trabalhar. Um encontro a mais após o primeiro dia seria muito útil para que o professor pudesse trabalhar resolução de problemas e problemas abertos. Questões nas quais se deve fornecer algumas variáveis não são comuns aos alunos. Não houve tempo para resolver nenhuma questão deste tipo no quadro, apenas algumas dúvidas foram tiradas nos espaços de tempo previstos no planejamento. Este ponto precisa ser corrigido em experiências futuras.

Em um encontro a mais também poderia haver uma preparação para as atividades previstas originalmente nos encontros 2 e 3 . Durante estas atividades pretendia-se que os alunos pensassem por si próprios, para que desenvolvessem habilidades para solucionar problemas. Contudo, em se tratando de uma atividade nova para os estudantes, percebe-se agora que faltou uma preparação anterior. Dificilmente os alunos têm a possibilidade de fazer uma atividade assim, construir algo presente no cotidiano a partir de poucas informações explicitamente dadas e usando conhecimentos da física.

Algumas dificuldades, frequentemente comentadas em artigos sobre a área temática, presentes na resolução de problemas por parte dos alunos, foram observadas. Cabe aqui relembrá-las, por serem úteis para a reflexão e para planejamento de aulas futuras. As principais dificuldades encontradas foram: os alunos não sabem identificar qual é a incógnita, não enxergam o problema num todo, e não trabalham metodicamente. Além disso, não identificam a necessidade de se usar assuntos estudados anteriormente no problema atual, no caso do assunto em questão, mudança de estado físico; não sabem o significado físico das grandezas, e não analisam se valores numéricos propostos para as grandezas têm sentido físico.

As dificuldades de não identificar a incógnita e não possuir uma imagem completa do problema, remetem aos primeiros quatro passos do roteiro para a resolução de problemas apresentado por Peduzzi (1997). Estes pontos também evidenciam a falta de atenção e de motivação para se resolver o problema, resultando em um trabalho não sistemático, uma resolução desleixada e meio sem saber o que se está fazendo. A motivação dos alunos deve então ser também trabalhada. Neste momento, fatores psicológicos, citados anteriormente, são importantes. Conhecer os alunos, as experiências escolares anteriores, até mesmo as dificuldades fora da escola, pode ajudar a escolher problemas que possam ser de interesse para os alunos, que possam estar relacionados ao seu cotidiano, que tenham contato com a sua realidade. 
A escola também deve trabalhar para que os alunos tenham condições de focar mais nos estudos. Investir na motivação é fundamental!

A não relação com outros assuntos estudados anteriormente evidenciam uma deficiência na consolidação destes. $O$ fato de não saberem o significado físico das grandezas, está relacionado, entre outras coisas, à falta de atenção e/ou de motivação, pois sem o interesse do aluno dificilmente há um esforço para o entendimento, além da dificuldade da relação dos conceitos físicos com as fórmulas matemáticas. Muitos alunos não enxergam que algumas letras podem assumir um conjunto de valores, ou que elas representam uma infinidade de valores, dentro de uma equação, enquanto que outras são constantes. As dificuldades em se trabalhar mais com letras do que com números, refletem este problema. Em resumo, muitos são acostumados a substituir os números pelas letras nas fórmulas e encontrar um valor para a incógnita. Não há um raciocínio, por exemplo, do que aconteceria se o valor de algum dado inicial fosse dobrado, o que seria mais facilmente obtido se a incógnita fosse isolada em função das outras letras (nona etapa do roteiro de Peduzzi (1997)).

A falta de análise de se os valores numéricos propostos para as grandezas físicas têm sentido físico, especialmente no caso de problemas abertos, remete ao mal conhecimento teórico e ao ponto 10 do roteiro do Peduzzi (1997). Falta também a interpretação dos resultados por parte dos alunos, fato que não é costume para eles. Também aqui a motivação dos alunos e o uso de problemas relacionados ao seu cotidiano podem ajudar na análise dos valores, pois serão de interesse e poderão ser próximos de valores já presentes na sua vida. A falta de análise dos valores e de interpretação dos resultados também pode estar relacionada ao que é de costume dos alunos. Guisasola et al. (2015) observa que muitos estudantes de física geral em universidades aprendem a resolver exercícios numéricos de diferentes tipos, mas em geral são incapazes de explicar o significado das suas próprias soluções. Acreditamos que o mesmo ocorra em outros níveis de ensino. Isto reflete a falta de prática, tanto por parte do aluno quanto por parte do professor, que não realça a importância de tal prática em suas aulas. Desta forma, os alunos podem não estar acostumados a analisar valores e a interpretar resultados.

Acreditamos que a falta de preparação para as atividades (problemas abertos) dos encontros 2 e 3 , contribuiu para as distrações dos alunos durante as atividades. Afirmamos isso pois pensamos que os alunos não entenderam o solicitado e devido aos grupos, as distrações com conversas alheias às atividades ficaram favorecidas. 
Ao não entender, os alunos perderam rapidamente o interesse. Reforçamos aqui que estas atividades, com a devida preparação, podem propiciar todos os benefícios citados nos trabalhos das áreas de resolução de problemas e problemas abertos.

Por último, acreditamos que a pouca experiência do estagiário em sala de aula contribuiu significativamente para que as atividades não acontecessem como esperado. Mais experiência na condução de atividades com os alunos será fundamental tanto para a construção de planos mais assertivos, como para a execução destes.

\section{CONSIDERAÇÕES FINAIS}

Os problemas abertos, como os propostos neste trabalho, exigem uma mudança na postura dos professores e dos alunos. Os professores precisam valorizar mais o processo na busca pelo desenvolvimento de um espírito investigativo, motivando e instigando seus alunos. Precisam assumir uma postura favorável ao protagonismo dos estudantes. Os estudantes precisam ser mais ativo nesse processo. Precisam assumir o papel de sujeitos do conhecimento (DELIZOICOV, ANGOTTI \& PERNAMBUCO, 2011). Na prática, para que isso ocorra, faz-se necessária uma preparação para se trabalhar este tipo de problema. O professor deve trabalhar em sala de aula a necessidade de se identificar o que é necessário para se obter uma resposta, de propor valores numéricos para as grandezas, de se trabalhar mais com letras e ainda deixar de olhar o erro de forma punitiva. "O contexto escolar deveria ser o local por excelência das tentativas próprias de solução de problemas [...] E nessa tarefa os erros, frutos de tentativas de operar com novos conceitos e procedimentos, têm um papel fundamental, posto que a partir de seu exame crítico desenvolve-se o discernimento" (CARVALHO, 1997).

Esse processo de resolução de problemas abertos pode ajudar os alunos no aprendizado teórico, na interpretação das letras nas fórmulas matemáticas e de seus significados físicos, no desenvolvimento de habilidades de construções de imagens, como um todo, das situações trabalhadas, na necessidade de se analisar os resultados e, por fim, na importância do desenvolvimento de um espírito investigativo. Mesmo alunos que já são bons solucionadores de problemas típicos de livros didáticos tradicionais, que possuem boa prática com fórmulas e valores, podem se beneficiar desse processo, pois, nestes casos, os conhecimentos conceitual e teórico podem ser deficientes. 
A resolução de problemas, principalmente de problemas abertos, pode ser trabalhada pouco a pouco ao longo do ano letivo e em vários momentos, com diversos conteúdos. Assim, os estudantes vão criando hábitos e desenvolvendo suas habilidades, enquanto que os professores vão aperfeiçoando suas estratégias e qualificando essa prática. Fatores psicológicos dos alunos também devem ser levados em conta no planejamento e no processo de ensino-aprendizagem como um todo.

$\mathrm{Na}$ investigação em questão, a falta de experiência prejudicou o planejamento e o andamento das atividades. O estágio é um bom lugar para se trabalhar isso. Assim, a resolução de problemas deve ser trabalhada nos cursos de formação de professores.

Concluímos então que a resolução de problemas, principalmente os abertos, é uma ferramenta útil em vários aspectos no processo de ensino-aprendizagem, além de ser de baixo custo material, ou seja, não demanda a presença de grandes recursos, podendo ser trabalhada em praticamente qualquer escola.

\section{Problem solving and ill-structured problems: An Investigation in Physics Education}

\section{Abstract}

This work talks about an investigation of problem solving in the context of physics teaching in a high school class, where the main goal was to analyze students' engagement in solving physics problems. The failures observed in tests based on problem solving show the necessity to work on this subject in the classroom by the teacher and the school. Students without a proper training should not be considered able to solve pencil and paper problems and ill-structured problems in physics. Solving ill-structured problems meets philosophical positions that advocate a more active student stance during the teaching-learning process. Among other benefits, problem solving also contributes to the learning of the theory, to make the class more dynamic and to form citizens more aware of the world around and the impact of their actions on it, even outside the classroom. We concluded, then, that problem solving, especially with ill-structured ones, is a useful tool in several aspects in the teaching-learning process, in addition to being of low material cost, that is, it does not demand many resources and it can be implemented in almost any school.

Keywords: problem solving, ill-structured problems, teacher education, engagement. 


\section{REFERÊNCIAS}

ABDULLAH, Helmi. Problem solving of Newton's second law through a system of total mass motion. Asia-Pacific Forum on Science Learning and Teaching, v.15, n.2, article 15, dez. 2014.

BARKOVICH, Mateo; CARREÑO, Alexandra. Un modelo para la distribución de semáforos en una calle como problema integrador en los cursos introductorios de las carreras de Ingeniería. Latin American Journal of Physics Education, v.7, n.1, p.63, mar. 2013.

BOY, Filipe Costa Batista; GARCIA, Letícia Silva. A importância de uma plataforma digital como suporte para aplicação da metodologia de Aprendizagem Baseada em Problemas em sala de aula. Revista Brasileira de Ensino de Ciências e Matemática, v. 1, n. 2, p. 142-154, 17 dez. 2018.

BRASIL. Orientações Curriculares Nacionais para o Ensino Médio - PCNEM: Ciências da Natureza, Matemática e suas Tecnologias. Brasília: MEC. 2006. Disponível em http://portal. mec.gov.br/seb/arquivos/pdf/book_volume_02_internet.pdf.

BRASIL. Orientações Educacionais Complementares aos Parâmetros Curriculares Nacionais para o Ensino Médio - PCN+: Física. Brasília: MEC. Disponível em http://www. sbfisica.org.br/arquivos/PCN_FIS.pdf.

CARVALHO, José Sérgio Fonseca de. As noções de erro e fracasso no contexto escolar: algumas considerações preliminares. In: Erro e fracasso na escola: alternativas teóricas e práticas. [S.l: s.n.], 1997.

CLEMENT, Luiz; TERRAZZAN, Eduardo A. Resolução de problemas de lápis e papel numa abordagem investigativa. Experiências em Ensino de Ciências, v.7, n.2, p.98-116, 2012.

DELIZOICOV, Demétrio; Angotti, José André; Pernambuco, Marta Maria. Ensino de Ciências: Fundamentos e Métodos. 4 ed. São Paulo. Editora Cortez, 2011.

DIAKIDOY, Irene-Anna N.; CONSTANTINOU, Constantinos P. Creativity in physics: Response fluency and task specificity. Creativity Research Journal, v.13, p.401-410, out. 2001.

ENGHAG, Margareta; Gustafsson, Peter; Jonsson, Gunnar. Talking Physics during Small-Group Work with Context-Rich Problems - Analysed from an Ownership Perspective. International Journal of Science and Mathematics Education, v.7, n.3, 455-472, 2009.

ERCEG, Natasa; AVIANI, Ivica; Mesic, V. Probing students' critical thinking processes by presenting ill-defined physics problems. Revista Mexicana de Fisica E, v.59, n.1, p.65-76, 2013.

GIL-PÉREZ, Daniel; Martinez-Torregrosa, Joaquín. La resolución de problemas de Física una didáctica alternativa. Madrid/Barcelona, Ediciones Vicens-Vives, 1987.

GIL-PEREZ, Daniel; DUMAS-CARRÉ, Andrée; CAILLOT, Michel; MARTINEZ-TORREGROSA, Joaquín; RAMÍREZ-CASTRO, Lorenzo. La resolución de problemas de lápiz y papel como actividad de investigación. Investigación em la Escuela, n.6, p.3-20, 1988.

GIL-PÉREZ, Daniel et al. Questionando a didática de resolução de problemas: elaboração de um modelo alternativo. Caderno Brasileiro de Ensino de Física, Florianópolis, v.9, n.1, p.7-19, jan. 1992.

GUISASOLA, Jenaro et al. Resolver ejercicios no es fácil. El papel de la metodología científica en la resolución de problemas de física. Rev. Bras. Ensino Fís., São Paulo, v.37, n.3, p.3508-1$3508-5$, set. 2015. 
HUNSCHE, Sandra; AULER, Décio. O professor no processo de construção de currículos: desafios no estágio curricular supervisionado em ensino de física. Revista Electrónica de Enseñanza de Las Ciencias, v.11, n.1, p.1-20, 2012.

KUHN, Thomas S. A estrutura das revoluções científicas. São Paulo: Perspectiva, 1987. p.232-233.

LABURÚ, Carlos Eduardo. Problemas abertos e seus problemas no laboratório de física: uma alternativa dialética que passa pelo discursivo multivocal e univocal. Investigações em Ensino de Ciências, v.8, n.3, p.231-256, 2003.

OLIVEIRA, Vagner; ARAUJO, Ives Solano; VEIT, Eliane Angela. Resolução de problemas abertos no ensino de física: uma revisão da literatura. Rev. Bras. Ensino Fís., São Paulo, v.39, n.3, e3402, 2017.

PEDUZZI, Luiz Orlando de Quadro. Sobre a resolução de problemas no ensino da Física. Caderno Brasileiro de Ensino de Física, Florianópolis, v.14, n.3, p.229-253, jan. 1997.

PIZZOLATO, Nicola; FAZIO, Claudio; MINEO, Rosa Maria Sperandeo; ADORNO, Dominique Persano. Open-inquiry driven overcoming of epistemological difficulties in engineering undergraduates: A case study in the context of thermal science. Physical Review Special Topics - Physics Education Research, v.10, 010107, 2014.

ROBINSON, A. W. Don't just stand there-teach Fermi problems!. Physics Education, v.43, n.1, p.83-87, 2008.

ROSA, Paulo R. S.; MOREIRA, Marco A.; BUCHWEITZ, Bernardo. Alunos bons solucionadores de problemas de Física: caracterização a partir de um questionário para análise de entrevistas. Revista Brasileira de Ensino de Física, v.14, n.2, p.94-100, 1992. 